\title{
A computer assisted method to obtain the prothrombin activation velocity in whole plasma independent of Thrombin decay processes
}

Citation for published version (APA):

Hemker, H. C., Willems, G. M., \& Beguin, S. (1986). A computer assisted method to obtain the prothrombin activation velocity in whole plasma independent of Thrombin decay processes. Thrombosis and Haemostasis, 56(1), 9-17. https://doi.org/10.1055/s-0038-1661594

Document status and date:

Published: 01/01/1986

DOI:

10.1055/s-0038-1661594

Document Version:

Publisher's PDF, also known as Version of record

Please check the document version of this publication:

- A submitted manuscript is the version of the article upon submission and before peer-review. There can be important differences between the submitted version and the official published version of record.

People interested in the research are advised to contact the author for the final version of the publication, or visit the DOI to the publisher's website.

- The final author version and the galley proof are versions of the publication after peer review.

- The final published version features the final layout of the paper including the volume, issue and page numbers.

Link to publication

\footnotetext{
General rights rights.

- You may freely distribute the URL identifying the publication in the public portal. please follow below link for the End User Agreement:

www.umlib.nl/taverne-license

Take down policy

If you believe that this document breaches copyright please contact us at:

repository@maastrichtuniversity.nl

providing details and we will investigate your claim.
}

Copyright and moral rights for the publications made accessible in the public portal are retained by the authors and/or other copyright owners and it is a condition of accessing publications that users recognise and abide by the legal requirements associated with these

- Users may download and print one copy of any publication from the public portal for the purpose of private study or research.

- You may not further distribute the material or use it for any profit-making activity or commercial gain

If the publication is distributed under the terms of Article 25fa of the Dutch Copyright Act, indicated by the "Taverne" license above, 


\title{
A Computer Assisted Method to Obtain the Prothrombin Activation Velocity in Whole Plasma Independent of Thrombin Decay Processes
}

\author{
H. C. Hemker, G. M. Willems and S. Béguin \\ From the Departments of Biochemistry and Biophysics, University of Limburg, The Netherlands, and the \\ Dept. of Hematology CHU Necker-Enfants Malades, Paris, France
}

\begin{abstract}
Key words
Prothrombin activation velocity - Thrombin generation velocity - Antithrombin activities $-\alpha_{2}$-Macroglobulin
\end{abstract}

\section{Summary}

A method is described that, on the basis of the time course of amidolytic activity after the triggering of thrombin generation in normal plasma, allows the calculation of the velocity of prothrombin conversion independent of thrombin inactivating processes.

It is shown how the reaction constants for the $\alpha_{2} \mathrm{M}$-dependent and the $\alpha_{2} \mathrm{M}$-independent thrombin inactivation processes can be obtained in a sample of whole plasma.

The method is verified by demonstrating that the experimentally observed time courses of residual prothrombin and of $\alpha_{2} \mathrm{M}$ thrombin complex coincide with those calculated from the time course of amidolytic activity, and by showing that the course of prothrombin conversion in plasma without $\alpha_{2}$-macroglobulin or AT III is adequately described if the $\alpha_{2} \mathrm{M}$ or AT III-dependent breakdown constants are taken zero in the calculations.

It appears that the inactivation of thrombin, endogenously generated in whole plasma, is about half as fast as that of exogenous thrombin added to the plasma.

A computer program is presented that carries out the relevant calculations.

\section{Introduction}

The thrombin generation curve is one of the oldest tools of the coagulation trade. It is the basis of the so-called two-stage prothrombin estimation $(1,2,3)$ but its roots go as far back as the very discovery of prothrombin (4). The rise and fall of thrombin concentration after triggering of coagulation in plasma results from the combined activity of the prothrombin activating enzyme complex (prothrombinase) and the thrombin inactivating processes, i. e. the binding of thrombin by antithrombins, such as antithrombin III and $\alpha_{2}$-macroglobulin $(5,6)$.

The general shape of the curve shows a short lag time and a fairly quick rise. After the maximum has been reached a gradual decline is observed that, if the clotting of fibrinogen is used to estimate thrombin, will eventually approach a zero level. Because the complex of a protease with $\alpha_{2}$-macroglobulin has a persistent activity towards small molecular weight substrates $(6-10)$ the final level of activity will not be zero if the thrombin concentration is determined with the aid of chromogenic substrates.

Correspondence to: Prof. Dr. H. C. Hemker, University of Limburg, Dept. of Biochemistry, P.O. Box 616, 6200 MD Maastricht, The Netherlands
The classical thrombin generation test suffers from an important drawback: the samples from the mixture in which thrombin is generated have to be tested immediately on a fibrinogen containing reagent. Estimation of low concentrations of thrombin tends to be very imprecise and time-consuming when clotting methods are used. It therefore is virtually impossible to achieve in this way a sampling pattern with enough measuring points and of sufficient accuracy over the whole time range. A detailed analysis of the thrombin generation curve obtained by this method is therefore impossible.

This article describes a method to obtain thrombin generation curves with sampling intervals that can be as small as $5 \mathrm{sec}$. The thrombin is measured by its action on a chromogenic substrate. It is shown how these curves can be used to compute the time course of the process that generates thrombin (prothrombinase) independently of the processes that inactivate thrombin (antithrombins). These calculations can be carried out with the aid of a personal computer.

The following abbrevations will be used: AT III = Antithrombin III; $\alpha_{2} \mathrm{M}=\alpha_{2}$-macroglobulin; Tris = tris (hydroxymethyl)aminomethane; EDTA = Ethylenediamino tetracetate; SBTI = Soybean Trypsin Inhibitor.

\section{Materials and Methods}

\section{Plasmas}

Blood from healthy donors was collected on $0.13 \mathrm{M}$ trisodium citrate; nine parts of blood to one part of citrate solution.

A first and a second centrifugation were performed at $3,000 \mathrm{~g}$, at $15^{\circ} \mathrm{C}$ for $15 \mathrm{~min}$. A third centrifugation was done at $4^{\circ} \mathrm{C}$, for one hour at $23,000 \mathrm{~g}$. The platelet free plasma thus obtained was stored at $-80^{\circ} \mathrm{C}$. It was checked that the clotting factors and the antiproteases were in the normal range. The clotting factors were determined according to refs. 11 and 12 . Radial immuno diffusion was used to estimate $\alpha_{2}$-macroglobulin and $\alpha_{1}$-antitrypsin (M. Partigen, Behring Werke, Germany). Antithrombin III was determined according to ref. 13 .

Defibrinated plasma was obtained by mixing an aliquot of plasma with 1:500 volume of a reptilase solution, letting a clot form for $10 \mathrm{~min}$ at $37^{\circ} \mathrm{C}$ and keeping the clotted plasma at $0^{\circ} \mathrm{C}$ for $10 \mathrm{~min}$. The fibrin formed was discarded by centrifugation $\left(10 \mathrm{~min}, 5000 \mathrm{~g}, 0^{\circ} \mathrm{C}\right.$ ) or by winding on a small plastic spatula. The concentrations of factors II, V, VII, VIII, IX, X, XI, and XII did not significantly change by the reptilase treatment. For the factors V and VIII series of dilutions $(1-10 \%)$ of the plasma before and after the treatment were compared. They showed clotting times that were identical within the limits of experimental error thus excluding the possibility that a combined effect of activation and inactivation of the factors accidently mimicked as identical clotting factors.

The euglobulin fraction from defibrinated plasma was obtained by acid precipitation at low ionic strength as described in ref. 11. The precipitate was dissolved in Michaelis buffer $\mathrm{pH} 7.35$ containing $0.02 \mathrm{M}$ trisodium citrate, so as to obtain a concentration of the clotting factor II, V, VII and $\mathrm{X}$ that was not lower than $50 \%$. No antithrombin activity could be demonstrated in this mixture. 
Thrombin was formed in the euglobulin fraction by the addition of human thromboplastin (1:240 final dilution) and $\mathrm{CaCl}_{2}$ (16 mM final conc.). The development of thrombin activity was measured as described later in this section.

Human brain thromboplastin was prepared as described in ref. 14. It was subsequently centrifuged at $2000 \mathrm{~g}$ for $15 \mathrm{~min}$ and stored in $0.1 \mathrm{ml}$ aliquots at $-20^{\circ} \mathrm{C}$. It was thawed and incubated at $37^{\circ} \mathrm{C}$ for one hour, then diluted as indicated with buffer A containing $100 \mathrm{mM}$ of $\mathrm{CaCl}_{2}$ and kept at room temperature. In this way it remained stable for at least $4 \mathrm{~h}$.

Reptilase was obtained from Laboratories Stago (Asnières, France), and prepared according to the indications of the manufacturer.

Soybean trypsin inhibitor (batch no 43 F-800) was obtained from Sigma (St. Louis, USA). A $10 \mathrm{mg} / \mathrm{ml}$ solution in buffer A was used.

Staphylocoagulase was prepared as described in Hendrix et al. (15). Chromogenic substrate for thrombin was H.D.-phe-pip-arg-pNA. 2 HCL (S2238, from Kabi, Sweden).

Other chemicals were the highest grade commercially available.

\section{Buffers}

A: $0.05 \mathrm{M}$ Tris- $\mathrm{HCl}, 0.1 \mathrm{M} \mathrm{NaCl} \mathrm{pH} 7.5$, with $0.5 \%$ egg albumin (Sigma)

$$
\text { B: Buffer A with } 20 \mathrm{mM} \text { EDTA. }
$$

\section{Inhibitor-Deficient Plasmas}

Plasma without $\alpha_{2} \mathrm{M}$ was obtained by addition of anti- $\alpha_{2} \mathrm{M}$ globulin to normal plasma and elimination of the immunoprecipitate. The $\gamma$-globulins were isolated according to Steinbuch et al. (16) from the serum of rabbits immunized against purified human $\alpha_{2} \mathrm{M}$ (gift from J. Tapon-Bretaudière). No $\alpha_{2} \mathrm{M}$ could be demonstrated by an immunoelectrophoretic method that would detect $\alpha_{2} \mathrm{M}$ at concentrations $>2 \%$ of the normal plasma concentration. Plasma without AT III was prepared by gently stirring $2 \mathrm{ml}$ of normal human plasma with $0.8 \mathrm{ml}$ of a slurry of sepharose to which anti ATIII was bound (gift from Dr. Tran Huu Tri, Basel) for $18 \mathrm{~h}$ at $4^{\circ} \mathrm{C}$. The antithrombin activity in the plasma after adsorbtion was not influenced by the addition of $1 \mathrm{U} / \mathrm{ml}$ of heparin.

\section{Determination of the Time Course of Amidolytic Activity}

An aliquot of plasma is defibrinated as indicated above. To $200 \mu \mathrm{l}$ of defibrinated plasma is added $50 \mu \mathrm{l}$ of buffer $\mathrm{A}$, that may contain the substances of which the influence on thrombin generation has to be investigated (e.g. heparins).

At zero time, thrombin generation is triggered by the addition of $50 \mu \mathrm{l}$ buffer $\mathrm{A}$ containing $100 \mathrm{mM}$ of $\mathrm{CaCl}_{2}$ and a suitable trigger of coagulation. In the experiments described here human brain thromboplastin, diluted as indicated, was used as a trigger. If necessary the volumes indicated may be proportionally altered. At fixed intervals $(10,15,20,30$ or $60 \mathrm{sec}$ ) after zero time, a $10 \mu \mathrm{l}$ aliquot of the mixture is added to a disposable plastic microcuvette containing $465 \mu \mathrm{l}$ of buffer B and $25 \mu \mathrm{l}$ of a $4 \mathrm{mM}$ solution of $\mathrm{S} 2238$ at $37^{\circ} \mathrm{C}$.

The aliquots are handled with a Microman pipette (Gilson, France). It is essential to keep the plunger of the pipette down after subsampling and to wipe the pipette tip carefully in order to avoid contamination of the incubation mixtures with EDTA from the buffer in the cuvette. Plastic tubes can be used instead of cuvettes but glass tubes adsorb thrombin and give unpredictable results.

A $15 \mathrm{sec}$ rhythm is easily managed, $10 \mathrm{sec}$ intervals require some practice. If shorter intervals are required one can make use of pipettes equipped with a pushbutton connected to an input gate of a personal computer (Apple IIe) programmed to record the moment of sampling. After sampling the cuvette is quickly and rigorously mixed on a Vortex mixer. After $120 \mathrm{sec}$ the reaction in the cuvette is stopped by adding $0.3 \mathrm{ml}$ of concentrated (98\%) acetic acid, the cuvette is again thoroughly mixed and can be kept at room temperature until reading. If a pushbutton pipette and automatic time recording is used for sampling, then stopping the reaction is also carried out with a time recording pipette.

The cuvettes are read at $405 \mathrm{nM}$ in a suitable spectrophotometer (LKB-Ultrospec). The generation of $\mathrm{p}$-Nitroaniline was linear in time up to an O.D. of 0.900 . If necessary, incubation times longer or shorter than two minutes can be used so as to obtain a suitable sensitivity and not to exceed 0.9 O.D.
The thrombin concentration data are processed by a computer program to obtain the time course of prothrombin conversion velocity. A full description of this procedure is to be found in the annexe.

\section{Determination of the Thrombin Breakdown Constant}

The same mixture as for thrombin generation curves is used, but with a volume of $44 \mu \mathrm{l}$ of buffer A instead of $50 \mu \mathrm{l}$. After 2 to $8 \mathrm{~min}$, at a moment that sufficient thrombin is formed, $6 \mu \mathrm{l}$ of SBTI solution $(10 \mathrm{mg} /$ $\mathrm{ml}$ ) is added to the main incubation mixture, so as to stop further prothrombinase activity. SBTI at this concentration could be shown to stop completely the activity of prothrombinase and not to influence the amidolytic activity of thrombin (17).

At the shortest possible intervals after addition of the SBTI solution, $10 \mu \mathrm{l}$ aliquots of the incubation mixture were added to cuvettes by the use of a time recording pipette. The cuvettes were further treated as described for the thrombin generation curves.

\section{Activation by Staphylocoagulase}

A solution of staphylocoagulase of $50 \mathrm{nM}$ is used. Of this solution $100 \mu \mathrm{l}$ was added to $100 \mu \mathrm{l}$ of a suitably diluted plasma sample. Normal plasma can be diluted $1: 50$. The incubation mixture remaining after a thrombin generation experiment is best diluted $1: 5$ or $1: 10$. The thrombin activity resulting from the formation of coagulase-thrombin is measured by adding $10 \mu \mathrm{l}$ of the mixture to a cuvette containing buffer $\mathrm{B}$ and chromogenic substrate as used for the thrombin generation curves. The staphylocoagulase-prothrombin complex has the same molar activity towards small molecular weight substrates as thrombin $(15,18)$. Commercially available staphylocoagulase preparations can be used. In that case the own amidolytic activity of the preparation should be determined and its activating capacity has to be checked on normal pooled plasma.

\section{Results}

\section{Experimental}

The method that we propose here has the purpose to determine the velocity of prothrombin conversion in whole plasma. To this end we determine the amidolytic activity that generates and disappears in plasma after suitable triggering of the coagulation process, using a substrate specific for thrombin. Then we analyse the time-activity curve by a mathematical procedure that separates the process of thrombin formation (prothrombinase activity) and thrombin inactivation (antithrombin activity). In order to carry out the calculations it is necessary to know the

Table 1 Activities and concentrations of $\alpha_{2} \mathrm{M}$-thrombin and prothrombin in serum

\begin{tabular}{lrllll}
\hline & & \multicolumn{2}{l}{$\begin{array}{l}\text { Activities } \\
\text { (nM thrombin eq) }\end{array}$} & $\begin{array}{l}\text { Concentrations } \\
(\mathrm{nM})\end{array}$ \\
\hline $\begin{array}{l}\text { Thromboplastin } \\
\text { dilution }\end{array}$ & $\mathrm{n}$ & $\begin{array}{l}\alpha_{2} \mathrm{M}-\mathrm{T} \\
(1)\end{array}$ & $\alpha_{2} \mathrm{M}-\mathrm{T}+\mathrm{SC}$ & $\begin{array}{l}\alpha_{2} \mathrm{M}-\mathrm{T} \\
(2)\end{array}$ & F II \\
\hline $1: 40$ & 10 & $117( \pm 2)$ & $265( \pm 5)$ & $65( \pm 6)$ & $148( \pm 5)$ \\
$1: 100$ & 4 & 123 & 280 & 69 & 157 \\
$1: 200$ & 4 & 109 & 273 & 61 & 162 \\
$1: 400$ & 10 & $111( \pm 5)$ & $266( \pm 8)$ & $62( \pm 7)$ & $155( \pm 9)$ \\
\hline
\end{tabular}

The activities were determined in the reaction mixtures of the experiments shown in Fig. 1 , between $t=10$ and $t=20$. They are expressed as the equivalent amount of thrombin that would give the same rate of conversion of chromogenic substrate. $\alpha_{2} \mathrm{M}-\mathrm{T}$ (1) is the spontaneous activity, $\alpha_{2} \mathrm{M}-\mathrm{T}+\mathrm{SC}$ is the total activity that could be elicited by addition of an excess of staphylocoagulase. $\alpha_{2} \mathrm{M}-\mathrm{T}$ (2) ist the concentration of the $\alpha_{2} \mathrm{M}$-thrombin complex obtained by multiplying the $\alpha_{2} \mathrm{M}-\mathrm{T}$ activity with the relevant constant (f, see text). FII is the prothrombin concentration obtained by subtraction of the first two colums. SEM are indicated when $\mathrm{n}=10$ 


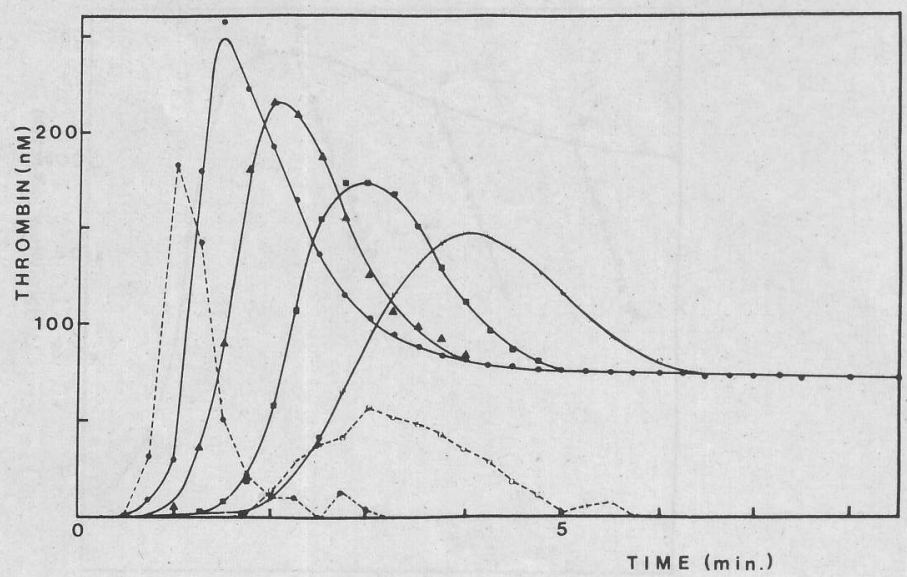

Fig. 1 Thrombin generation and the rate of thrombin formation in normal plasma triggered with different dilutions of thromboplastin. The reaction mixture consisted of $240 \mu \mathrm{l}$ defibrinated plasma $60 \mu \mathrm{l}$ buffer and $60 \mu \mathrm{l}$ thromboplastin diluted as follows $1 / 40(\mathbf{O}) ; 1 / 100(\mathbf{\Delta}) ; 1 / 200$ (四); $1 / 400(\mathrm{O})$. The dotted lines represent the thrombin generation velocities of the $1 / 40$ and $1 / 400$ curves resp. The scale for these curves is the thrombin generation velocity in $\mathrm{nM} \cdot \mathrm{min}^{-1}$

reaction constants of the breakdown processes. In the first part of this section we will discuss how these data are obtained. In the second part we verify the mathematical model.

\section{The Thrombin Generation Curve and the Reaction Constants}

Fig. 1 shows the thrombin activities generated in normal plasma by different dilutions of tissue thromboplastin. As a rule the standard derivation of each point is below $4 \%$ except for the points located in the steep rising parts of the generation curve. With the aid of pipettes provided with a signalling pushbutton connected to an input port of an Apple IIe computer we could estimate the experimental error in the sampling time to be between 0.4 and $1 \mathrm{sec}$. In the horizontal parts of the curve the coefficient of variation of the thrombin determination is $2.75 \%$.
When the tangent of the curve is steep, the time error adds significantly to the overall error so as to make it $15-18 \%$ at tangents exceeding 1000 O.D.U. $\min ^{-1}$. With the aid of the time recording pipettes it is possible to eliminate the time error and to obtain almost perfectly overlapping curves in repeated experiments.

The amounts of residual prothrombin left in the mixtures after the amidolytic activity has reached a steady end-level, were determined with staphylocoagulase (Table 1). They are apparently not dependent upon the variations in velocity of thrombin generation induced by dilution of thromboplastin.

From Fig. 2 it appears that thrombin generation can be resumed in the course of the experiment if purified human prothrombin is again added. The method thus determines thrombin generation velocities that are dependent upon both prothrombin concentration and prothrombinase activity.

Fig. 3 shows experiments in which the breakdown constant of thrombin in plasma was determined. The decay curve of thrombin generated endogenously in plasma was obtained by stopping the factor $\mathrm{X}_{\mathrm{a}}$ activity in thrombin generating plasma by addition of SBTI and measuring the thrombin disappearance (see methods section). Alternatively $200 \mathrm{nM}$ of thrombin that had been formed in a euglobulin mixture was added at zero time to defibrinated plasma diluted in the same way as the reaction mixture, SBTI included. In the latter case the decay was two fold quicker. The slower decay of endogenously formed thrombin cannot be attributed to ongoing thrombin formation because the amount of prothrombin that can be demonstrated with staphylocoagulase in the plasma does not change after the moment of stopping the reaction with SBTI (results not shown). During the course of thrombin generation the decay constant of thrombin does not change (Fig. 4), showing that in the course of the experiment there is not a time-dependent change in the properties of thrombin that could explain the difference in half-life time. For the moment we have no explanation for this phenomenon (see discussion)

The form of the decay curve is adequately described by a logarithmic approach to a steady end level (Figs. 3 and 4). From experiments like these overall decay constants can be obtained. This overall constant $\left(k_{\text {exp }}\right)$ is equal to the sum of the $\alpha_{2} M-$

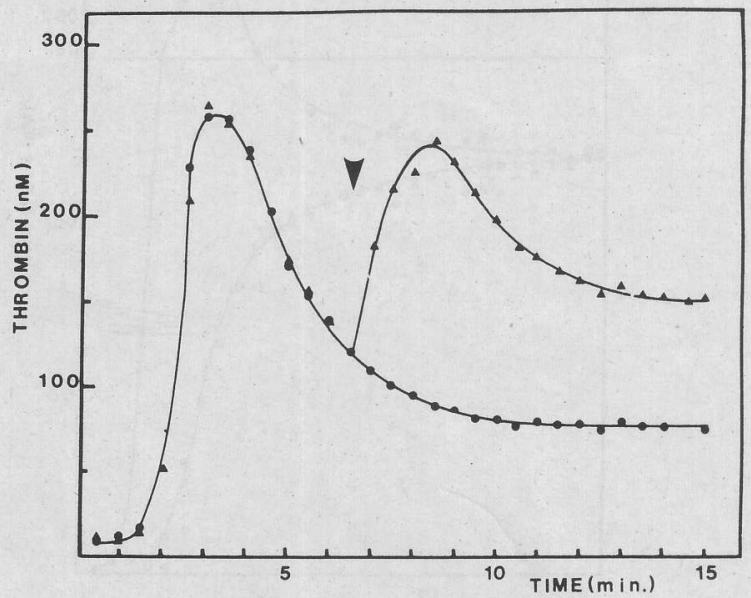

Fig. 2 Effect of addition of prothrombin during thrombin generation. To a thrombin generation experiment as in Fig. 1 (thromboplastin dilution 1/40) at $7 \mathrm{~min}$ (arrow) $1500 \mathrm{nM}$ of purified human prothrombin was added

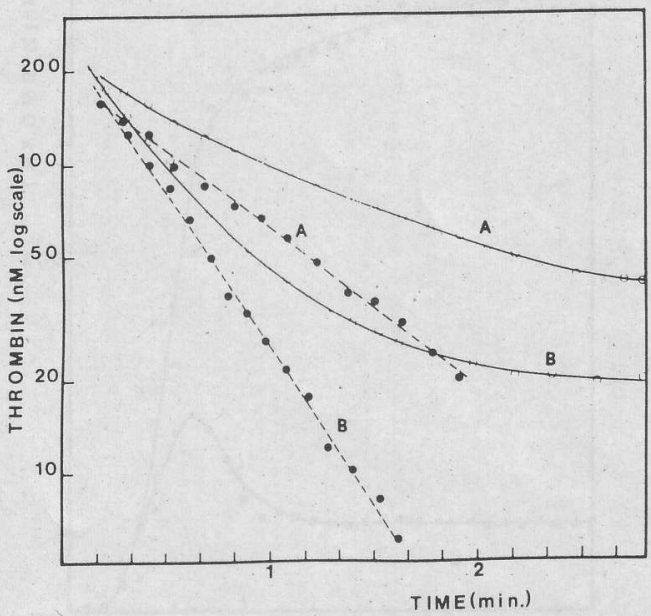

Fig. 3 Thrombin inactivation in plasma. A. (O-O) Decay of endogenous amidolytic activity after addition of SBTI in a standard thrombin generation experiment, $3 \mathrm{~min}$ after triggering the reaction with thromboplastin $1 / 40$. (-) The same data after subtraction of the steady endlevel of activity. B. (O-O) Decay of amidolytic activity of $200 \mathrm{nM}$ exogenous thrombin. (-) The same data after subtraction of the steady end-level of activity 


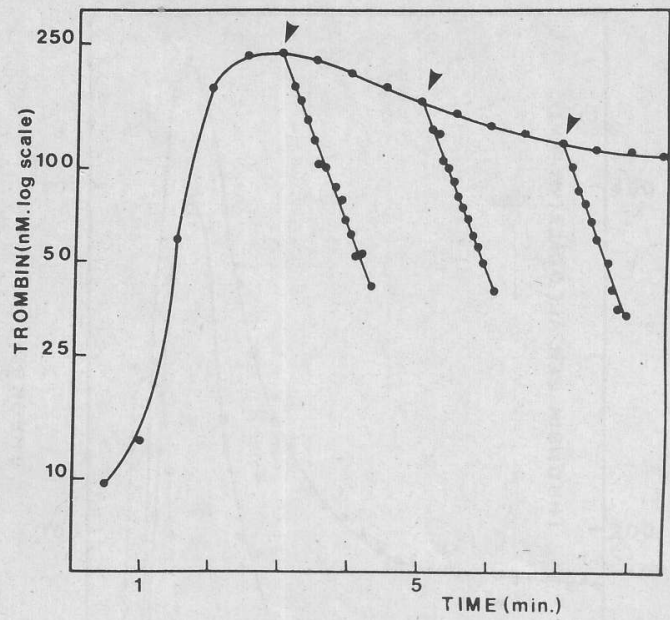

Fig. 4 Decay of endogenous thrombin at different intervals after the start of thrombin generation. In thrombin generation experiments triggered with thromboplastin $1 / 40$, SBTI was added at $t=3,5$ and $7 \mathrm{~min}$. The decay constants observed were $1.24,1.17$ and 1.23 respectively. The data are plotted on a log scale after subtraction of the steady end-levels

dependent decay constant $\left(\mathrm{k}_{1}\right)$ and the non- $\alpha_{2} \mathrm{M}$-dependent constant $\left(\mathrm{k}_{2}\right)$, mainly due to antithrombin III. Table 2 lists these constants for various kinds of normal and deficient plasma. Also, in this table the ratio of the amount of prothrombin consumed during the experiment (i.e. the total amount of thrombin formed) and the amount eventually taken up by $\alpha_{2} \mathrm{M}$ is given, as well as the values of $k_{1}$ and $k_{2}$ that can be calculated from these data. For this calculation it is necessary to know the value of $\mathrm{f}$; i. e. the ratio of the amidolytic activity of one mole of the $\alpha_{2} \mathrm{M}$-thrombin complex to one mole of free thrombin. This value was obtained by preparing thrombin in a euglobulin precipitate of defibrinated plasma and estimating its activity. Then an excess of an $\alpha_{2}$ macro-

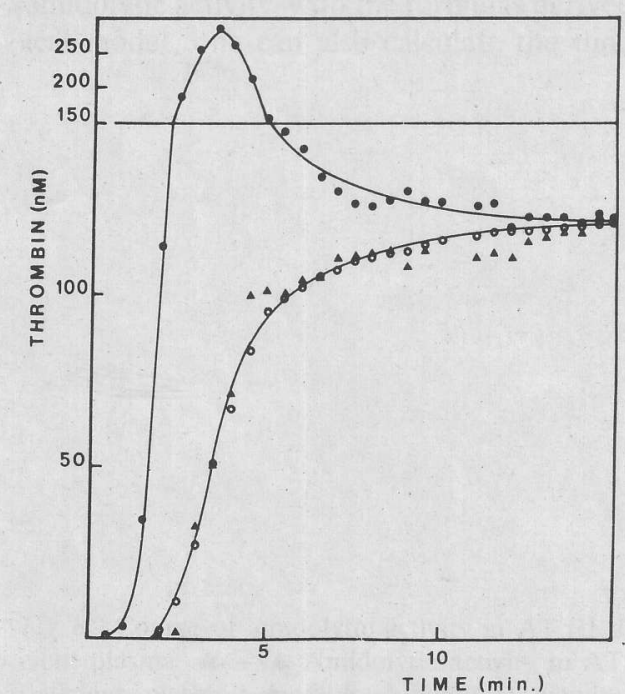

Fig. 5 Comparison of observed and computed levels of the $\alpha_{2} \mathrm{M}$ thrombin-complex. A standard thrombin generation experiment was carried out. Thromboplastin diluted 1:40 was used as a trigger. From the amidolytic activity $(-)$ the concentration of $\alpha_{2} \mathrm{M}-\mathrm{T}$ complex was computed (O). The levels of $\alpha_{2} \mathrm{M}-\mathrm{T}$ complex found experimentally are represented
Table 2 Reaction constants of inactivation in protease-inhibitor deficient plasmas

\begin{tabular}{llllll}
\hline Plasma & Dil. & $\begin{array}{l}\mathrm{k}_{\text {exp }} \\
\left(\mathrm{min}^{-1}\right)\end{array}$ & $\mathrm{R}_{\text {exp }}$ & $\begin{array}{l}\mathrm{k}_{1} \\
\left(\mathrm{~min}^{-1}\right)\end{array}$ & $\begin{array}{l}\mathrm{k}_{2} \\
\left(\mathrm{~min}^{-1}\right)\end{array}$ \\
\hline Control & 1.00 & 1.260 & 0.271 & 0.342 & 0.920 \\
\hline$\alpha_{2} \mathrm{M}$ def. & 0.78 & 0.733 & - & - & 0.733 \\
Control & & 0.856 & 0.236 & 0.200 & 0.756 \\
\hline $\begin{array}{l}\text { AT III def. } \\
\text { Control }\end{array}$ & 0.45 & 0.249 & - & $\left.0.167^{1}\right)$ & $\left.0.082^{2}\right)$ \\
\hline $\begin{array}{l}\text { Double def. } \\
\text { Control }\end{array}$ & 0.32 & 0.058 & - & - & 0.460 \\
\hline
\end{tabular}

Dil.: Dilution due to immunoadsorption, the control plasmas were diluted to the same extent

$\mathrm{k}_{\text {exp }}$ : Overall decay constant observed $\left(\mathrm{min}^{-1}\right)$

$\mathrm{R}_{\text {exp }}$ : Ratio of $\alpha_{2} \mathrm{M}-\mathrm{T}$ to At III-T in the control plasma

$\mathrm{k}_{1}$ and $\mathrm{k}_{2}$ : Pseudo first order reaction constants of the complexation of thrombin with $\alpha_{2} \mathrm{M}$ and non- $\alpha_{2} \mathrm{M}$ respectively $\left(\mathrm{min}^{-1}\right)$

$\left.{ }^{1}\right)$ Obtained from the double deficient plasma (accounting for the difference in dilution)

${ }^{2}$ ) Obtained by subtracting $\mathrm{k}_{1}$ from $\mathrm{k}_{\exp }$

globulin preparation devoid of AT III activity was added and the residual amidolytic activity was determined, $\mathrm{f}$ was estimated to be $0.558 \pm 0.043(\mathrm{n}=10 ;$ S.E.M.) (cf. Table 1).

\section{Verification of the Model}

The adequacy of our model was tested in two fundamentally different ways a) by comparing the time course of reaction products as predicted by the model with those actually found, b) by studying the effect of selective elimination of AT III and/or $\alpha_{2} \mathrm{M}$.

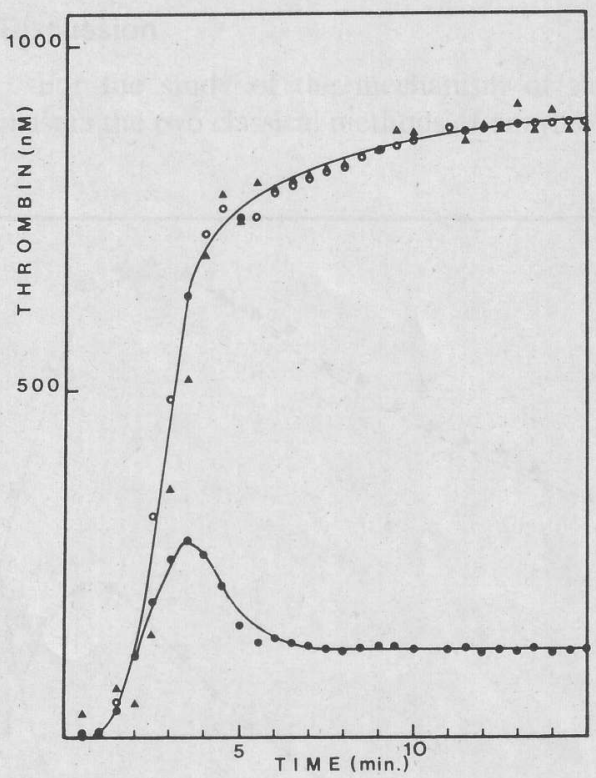

Fig. 6 Comparison of observed and computed levels of consumed prothrombin. In a standard thrombin generation experiment (trigger: thromboplastin $1: 40$ ) the amount of prothrombin converted (O) was computed from the amidolytic activities (-) and compared to the difference between the original amount of prothrombin and amount remaining during the time course of activation $(\mathbf{A}$ 


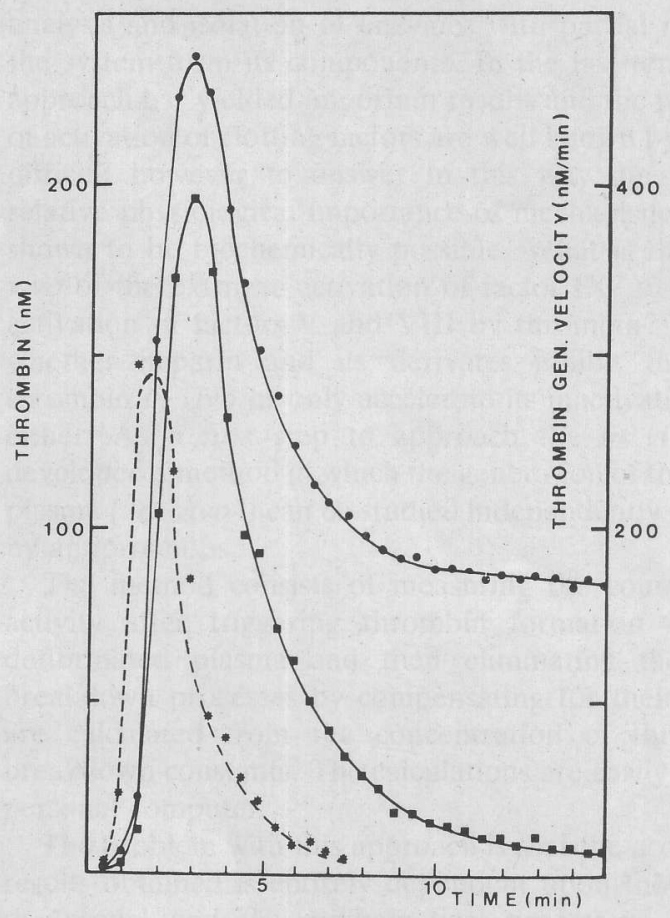

Fig. 7 Course of amidolytic activity in $\alpha_{2}$-macroglobulin deficient plasma. Amidolytic activity in $\alpha_{2} \mathrm{M}$ deficient plasma. Amidolytic activity in control plasma. Dotted line: Thrombin generation velocity calculated from the amidolytic activity curves. $\bigcirc$ : points obtained from the $\alpha_{2} \mathrm{M}$ deficient plasma. 5 : points obtained from the control plasma. The constants used for calculation are given in Table 1

In Fig. 5 two sets of experimental data are plotted. The overall amidolytic activity as determined by our standard procedure (O) and the level of $\alpha_{2} \mathrm{M}$-thrombin ( $\left.\boldsymbol{\Delta}\right)$. The latter was determined by subsampling from the reaction mixture into a solution containing an excess $(1 \mathrm{U} / \mathrm{ml})$ of heparin and $20 \mathrm{mM}$ EDTA. In this mixture the generation of thrombin stops immediately and, because the half-life of thrombin is $<10 \mathrm{sec}$, the residual activity measured after $10-20 \mathrm{~min}$ is due to the amount of $\alpha_{2} \mathrm{M}$-bound thrombin that was present at the moment of subsampling. From the data on amidolytic activity, with the formulas derived from the mathematical model, one can also calculate the time course of the $\alpha_{2} \mathrm{M}$ - thrombin concentration (O). From Fig. 5 it is seen that the calculated values and the values actually determined coincide within the limits of experimental error. Fig. 6 also shows the equivalence of a set of experimental and calculated concentrations, viz. those of the total amounts of prothrombin converted into thrombin. Experimentally these concentrations were determined by subsampling into a mixture containing 20 mM EDTA, $1 \mathrm{U} / \mathrm{ml}$ of heparin and $2 \mu \mathrm{M}$ of staphylocoagulase. In this mixture prothrombin conversion into thrombin stops, the thrombin present is inactivated by AT III and the prothrombin present converts quickly (second order rate constant $3.3 \times 10^{6} \mathrm{M}^{-1} \mathrm{~s}^{-1}$; [12] into the amidolytically active prothrombin-staphylocoagulase complex that is not inactivated by AT III. Thus one obtains the amount of residual prothrombin (after subtraction of the activity due to $\alpha_{2} \mathrm{M}$-thrombin determined independently) while the amount of prothrombin converted into thrombin is found by subtraction from the starting level. The equivalence between the concentrations found experimentally and those derived from the amidolytic activity via the kinetic model is again satisfactory.

A different approach to test the validity of the model is shown in Figs. 7 and 8. Here the inactivation system of the plasma was modified by selective immunoadsorbtion of $\alpha_{2}$-macroglobulin and AT III respectively. Control plasmas were obtained by treating normal plasma in a comparable way with a gammaglobulin fraction from serum from non-immunised rabbits and adjustment of the dilution if necessary.

In Table 2 it is shown that the decay constants calculated for the non-deficient plasma are identical to those found experimentally in the deficient plasmas, if one allows for a small amount of inhibition that is due to neither $\alpha_{2} \mathrm{M}$ or AT III.

In Fig. 7 the thrombin activity curves obtained with the $\alpha_{2} \mathrm{M}$ deficient plasma and its control are shown as well as the thrombin generation velocity curves obtained from them, using the relevant constants from Table 2. In Fig. 8 the same is done for the AT III deficient plasma. In both Fig. 7 and Fig. 8 the thrombin generation velocity curves obtained with the deficient and the control plasmas superimpose within the limits of experimental error, as would be expected from the model.

\section{Discussion}

For the study of the mechanism of thrombin formation in plasma the two classical methods of enzymology are open, kinetic
Fig. 8 Course of amidolytic activity in AT III deficient plasma. deficient plasma. $\star---\star$ Amidolytic activity in control plasma. Drawn line: Thrombin generation velocity calculated from the amidolytic activity curves. $\mathbf{A}$ : points obtained from the AT III deficient plasma. : points obtained from the control plasma. The constants used for calculation are given in Table 2

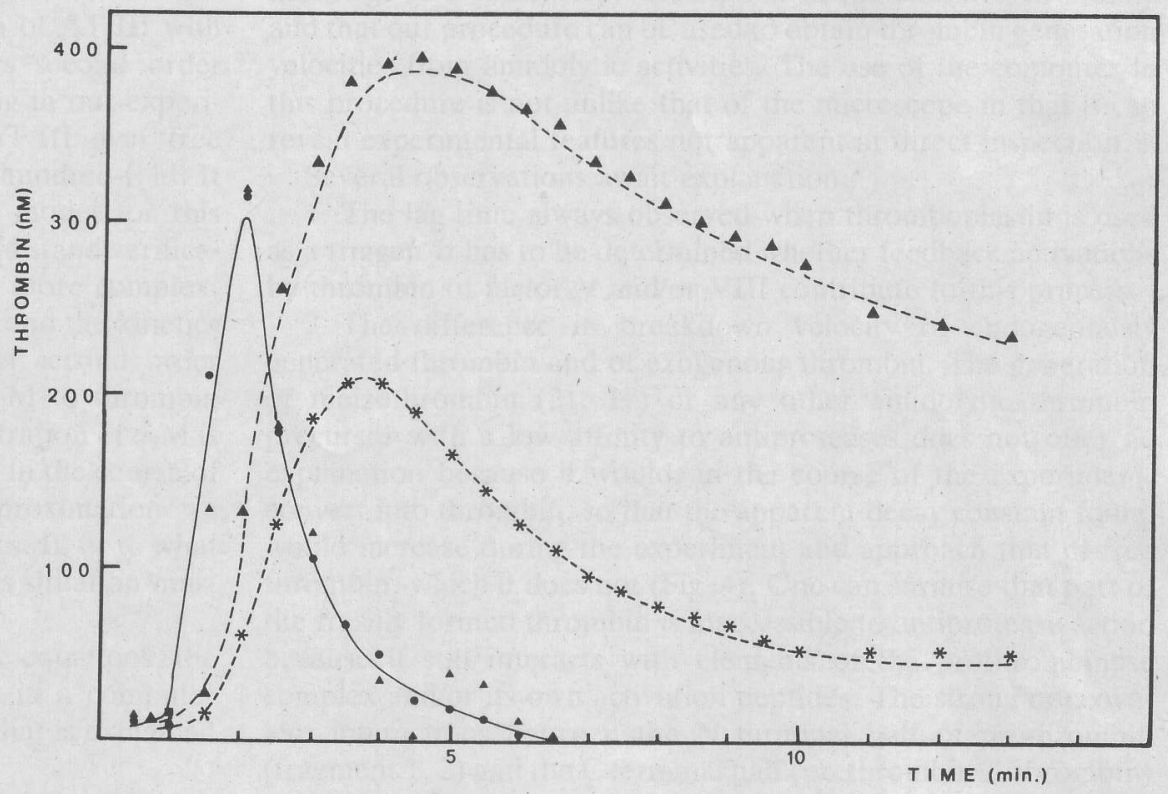


analysis and isolation of enzymes with partial reconstruction of the system form its components. In the last ten years the latter approach has yielded important results and the main mechanisms of activation of clotting factors are well known by now. It remains difficult however to answer in this way questions about the relative physiological importance of mechanisms that have been shown to be biochemically possible. What is the importance in vivo of the extrinsic activation of factor IX? or of the feedback activation of factors V and VIII by thrombin? The question of whether heparin and its derivates inhibit the formation of thrombin in vivo or only accelerate its inactivation is not settled either. As a first step to approach the in vivo situation we developed a method in which the generation of thrombin in whole plasma ("ex vivo") can be studied independently of its breakdown by antiproteases.

The method consists of measuring the course of amidolytic activity after triggering thrombin formation in a sample of defibrinated plasma and then eliminating the effect of the breakdown processes by compensating for their velocities, that are calculated from the concentration of thrombin and the breakdown constants. The calculations are easily carried out on a personal computer.

The problem with this approach is that the acceptability of the results obtained is entirely dependent upon the acceptability of the model and the mathematical procedure. Therefore it is important to test extensively the validity of the method.

We assume that the situation in the plasma when thrombin generates can be depicted by the following diagram:

$$
\begin{gathered}
\text { prothrombinase } \\
\text { prothrombin } \rightarrow \text { thrombin } \stackrel{\mathrm{k}_{1}}{\rightarrow} \alpha_{2} \text { M-thrombin } \\
\qquad \downarrow \mathrm{k}_{2}
\end{gathered}
$$$$
\text { inactive thrombin }
$$

The assumptions at the basis of the kinetic model are:

1. Thrombin breakdown occurs via two processes, one (caused by AT III and others antiproteases) leading to inactive products, the other ( $\alpha_{2} \mathrm{M}$-dependent) leading to a product with a residual amidolytic activity.

2. Both reactions are of pseudo first order with regard to thrombin.

It has been demonstrated that the interaction of AT III with thrombin is a bimolecular reaction and shows second order kinetics $(19,20)$. Under the conditions prevailing in our experiments there is at least a ten-fold excess of AT III over free thrombin and the excess of $\alpha_{1}$-antithrombin is a hundred-fold. It therefore seemed reasonable to try whether a model for this reaction based on pseudo first order kinetics would stand verification. The case of $\alpha_{2} \mathrm{M}$-dependent inactivation is more complex. Here the stoichiometry of the reaction is variable and the kinetics of the reaction are complicated $(20,6-10)$, yet second order reaction kinetics describe the situation if the $\alpha_{2} \mathrm{M}$ to thrombin ratio is higher than 2 to 1 (20). The initial concentration of $\alpha_{2} \mathrm{M}$ is $2 \mu \mathrm{M}$. No more than $300 \mathrm{nM}$ of this is complexed in the course of the experiment (Figs. 1 and 5). As a first approximation we therefore again assumed pseudo first order kinetics. If, or to what extent it is indeed an adequate description of this situation must follow from the experiments.

The translation of the reaction model into rate equations, the solution of these equations and their utilization in a computer program is a technical problem in mathematics, that is explained in the annexe and will not be discussed here.
The following qualitative arguments support the correctness of the model:

a. The partition between the AT III- $\mathrm{II}_{\mathrm{a}}$ complex and the $\alpha_{2} \mathrm{M}$ $\mathrm{II}_{\mathrm{a}}$ complex of the thrombin generated in an experiment is independent of the course of thrombin generation. This can be seen in Fig. 1 and Table 1, where the total amount of prothrombin as well as the levels of $\alpha_{2} \mathrm{M}-\mathrm{II}_{\mathrm{a}}$ eventually obtained are independent of the dilution of thromboplastin used. Our model predicts such behaviour (formula 8).

b. The decay of thrombin activity is characterized by a logarithmic approach to a steady end-level (Fig. 3). This proves the pseudo first order character of the breakdown constants (formula 4c).

c. The breakdown constant of thrombin does not change over the experiment (Fig. 4).

d. The level of activity remaining in the plasma after activation is explained by the level of $\alpha_{2} \mathrm{M}-\mathrm{II}_{\mathrm{a}}$ present (Fig. 5), in the absence of $\alpha_{2} \mathrm{M}$, the activity approaches the zero level (Fig. 7).

In the absence of both $\alpha_{2} \mathrm{M}$ and AT III there is a residual antithrombin activity of about $18 \%$ of the total (Table 2). This activity is not heparin dependent and consumes thrombin in a pseudo first order process (results not shown). In our formulas this decay is included in the AT III dependent decay $\left(\mathrm{k}_{2}\right)$. This inhibition activity is presumably due to $\alpha_{1}$ antitrypsin and other antiproteases.

From the observations ( $a$ to d) it can be concluded that the qualitative features of our model are supported by the experiments. The validity of our model is further corroborated by the similarity of the concentration courses calculated and those actually observed. In principle the time courses of all the reactants can be computed from the time course of the amidolytic activity. In practise the amounts of remaining prothrombin and of the $\alpha_{2}$ M-thrombin complex can be determined independent of amidolytic activity, thus offering the opportunity to compare the results of the calculation with the time-course of concentrations actually found. Figs. 5 and 6 shows that the observed and the computed points seem to follow the same curve.

Further qualitative arguments for the correctness of our procedure can be derived from Figs. 7 and 8 . Here it is seen that the velocities of thrombin generation computed from plasma specifically deficient in either $\alpha_{2} \mathrm{M}$ or in AT III coincide with those of the control plasma if the respective breakdown constants are eliminated from the computation.

We conclude that, within the limits of experimental error our model gives a satisfactory description of the situation in plasma and that our procedure can be used to obtain thrombin generation velocities from amidolytic activities. The use of the computer in this procedure is not unlike that of the microscope in that it can reveal experimental features not apparent at direct inspection.

Several observations await explanation:

1. The lag time always observed when thromboplastin is used as a trigger. It has to be determined whether feedback activations by thrombin of factor $\mathrm{V}$ and/or VIII contribute to this process.

2. The difference in breakdown velocity of endogenously generated thrombin and of exogenous thrombin. The generation of meizothrombin $(21,17)$ or any other amidolytic thrombin precursor with a low affinity to antiproteases does not offer an explanation because it would, in the course of the experiment; convert into thrombin, so that the apparent decay constant found would increase during the experiment and approach that of free thrombin, which it does not (Fig. 4). One can surmise that part of the freshly formed thrombin is inaccessible to antiprotease action because it still interacts with elements of the prothrombinase complex and/or its own activation peptides. The strong noncovalent interactions between the $\mathrm{N}$ terminal half of prothrombin (fragment 1,2) and the $\mathrm{C}$ terminal half (prethrombin 2, thrombin) 
(22) make such interactions not a priori unlikely. This problem is at present under investigation. The same phenomenon probably explains why the pseudo order rate constants that we find for endogenous thrombin breakdown in whole plasma are below the lower limits of ranges found in the literature with free thrombin and in (partly) purified systems. For $\alpha_{2} \mathrm{M}$ we found $0.342 \mathrm{~min}^{-1}$ (Table 1) compared to $0.4-0.8 \mathrm{~min}^{-1}$ in the literature. For AT III the value was $0.920 \mathrm{~min}^{-1}$ compared to $1.4-3.6 \mathrm{~min}^{-1}(6-10,23)$. The value of 0.09 for the decay constant of thrombin in the presence of the normal plasma concentration of $\alpha_{2} \mathrm{M}$ that can be calculated from ref. 20 , has been supposed by others to be based on an underestimation of the second order rate constant of this inhibition (10).

3. The model behaves as if the inhibitory capacity of $\alpha_{2} M$ is immediately available, although it is known that this molecule has to be activated by a proteolytic enzyme, e. g. by the proteolytic enzyme that it will complex with (5, 6 and references therein).

4. Even though prothrombinase is not exhausted (Fig. 2), the reaction comes to a stop when $5-10 \%$ of the original prothrombin is left. This suggests the possibility of product inhibition of prothrombin activation in whole plasma. Our results indicate that in $2: 3$ diluted normal platelet free plasma (our standard system) the pseudo first order rate constant of $\alpha_{2} \mathrm{M}$, AT III and non- $\alpha_{2} \mathrm{M}$ non-ATIII antiproteases contribute $23 \%, 64 \%$ and $13 \%$ to the overall disappearance rate of endogenous thrombin. This is in accordance with the $20-30 \%$ of plasma antithrombin activity assigned to $\alpha 2 \mathrm{M}$ by several authors $(10,19,20)$.

We think that our method may be a valuable means to investigate the physiology of thrombin generation in whole plasma and to study the influence of antithrombotic drugs on, as well as the pathological changes of this process. In the latter case additional studies, such as the estimation of prothrombin activation peptides may be necessary.

The procedure we propose can also be applied to the study of

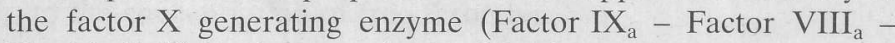
Phospholipid) in plasma on basis of the factor $\mathrm{X}_{\mathrm{a}}$ levels observed.

\section{Acknowledgements}

This work has partly been financed by grants from the "Nederlandse Thrombosestichting" and the "Fondation de France". Partly it was carried out during a sabattical leave of one of the authors (H.C.H.) at the Dept. of Hematology CHU Necker-Enfants Malades (Paris). We thank Mme. J. Tapon-Bretaudière for a gift of purified $\alpha_{2}$-Macroglobulin and Dr. Tran Huu Tri for the sepharose-bound anti AT-III.

\section{References}

1 Wagner R H, Graham J B, Penick G D, Brinkhous K M. Estimation of prothrombin by the two stage method. In: Blood coagulation, Hemorrhage and Thrombosis. Tocantins M L, Kazal L A (eds) Academic Press, New York - London 1965.

2 Biggs R, Macfarlane R G. Human blood coagulation and its disorders. Blackwell Scientific Publications, Oxford 1967

3 Hemker H C, Hemker P W, v d Torren K, Devilée P P, Hermens W Th, Loeliger E A. The evaluation of the two-stage prothrombin assay. Thromb Diathes Haemorrh 1971; 25: 545-54.

4 Pekelharing C A. Over de betrekking van het fibrineferment van het bloedserum tot de nucleoproteide van het bloedplasma. Versl Kon Acad Wetensch Amsterdam 1895; 3: 272-97.

5 Travis J, Salvesen G S. Human plasma proteinase inhibitors. Ann Rev Biochem 1983; 52: 655-709.

6 Rosenberg R D, Harpel P C. $\alpha_{2}$-Macroglobulin and antithrombinheparin cofactor: modulators of hemostatic and inflammatory reactions. Prog Hemost Thromb 1976; 3: 145-98.

7 Barret A J, Starkey P M. The interaction of $\alpha_{2}$ macroglobulin with proteinase. Biochem J 1973; 133: 709-15.
8 Harpel P C. Studies on human plasma $\alpha_{2}$-macroglobulin enzyme interactions. Evidence for proteolytic modification of the subunit chain structure. J Exp Med 1973; 138: 508-21.

9 Rinderknecht H, Feling R M, Geokas M C. Effect of $\alpha_{2}$-macroglobulin in some kinetic parameters of trypsin. Biochim Biophys Acta 1975; 377: $150-65$.

10 Fischer A M, Tapon-Bretaudière J, Bros A, Josso F. Respective roles of antithrombin III and $\alpha_{2}$-macroglobulin in thrombin inactivation. Thromb Haemostas 1981; 45: 51-4.

11 Josso F, Prou-Wartelle O. Exploration de l'hémostase. In: Techniques en hématologie. Alagille D et al. (eds). pp. 101-208. Flamarion, Paris 1972.

12 van Dam-Mieras M C E, Muller A D, van Dieijen G, Hemker H C. Methods of enzymatic analysis. Enzymes 3: Peptidases, proteinase and their inhibitors. Verlag Chemie, Weinheim 1984; 5: 352-94.

$13 \varnothing$ degard O R, Lie M. On the use of chromogenic substrates for the study of coagulation inhibitors. Haemostasis 1978; 7: $121-6$.

14 Owren P A, Aas K. The control of dicumarol therapy and the quantitative determination of prothrombin and proconvertin. Scand J Clin Lab Invest 1951; 3: 201-18.

15 Hendrix H, Lindhout T, Mertens K, Engels W, Hemker H C. Activation of human prothrombin by stoichiometric levels of staphylocoagulase. J Biol Chem 1983; 258: 3637-44.

16 Steinbuch M, Audran R. Isolement de l'immunoglobuline IgG du plasma humain à l'aide de l'acide caprylique. Rev Franç Etud clin biol 1969; 14: 1054-8.

17 Lindhout T, Baruch D, Schoen P, Franssen J, Hemker H C. Thrombin generation and inactivation of antithrombin III and heparin. (Submitted for publication).

18 Kawabata S, Morita T, Iwanaga S, Igarashi H. Staphylocoagulasebinding region in human prothrombin. J Biochem 1985; 97: 329-31.

19 Rosenberg R D, Damus P S. The purification and mechanism action of human antithrombin-heparin cofactor. J Biol Chem 1973; 248: 6490-505.

20 Downing M R, Bloom J W B, Mann K G. Comparison of the inhibition of thrombin by three plasma protease inhibitors. Biochemistry 1978; 17: 2649-53.

21 Rosing J, Zwaal R F A, Tans G. Formation of meizothrombin as an intermediate in Factor $\mathrm{X}_{\mathrm{a}}$-catalyzed prothrombin activation. J Biol Chem 1986; (In press).

22 Esmon C T, Jackson C M. The conversion of prothrombin to thrombin. IV. The function of the fragment 2 region during activation in the presence of factor V. J Biol Chem 1974; 249: 7791-7.

23 Jesty $\mathrm{J}$. The kinetics of inhibition of thrombin by antithrombin in the presence of components of the hemostatic systems. Blood 1985; 66: 1189-95.

24 Hemker H C, Willems G, Béguin S. Thrombinoscope, a personal computer program for the analysis of thrombin generation curves. Computers in Biol and Med. (Submitted).

Received February 24, 1986 Resubmitted May 1, 1986

Accepted May 2, 1986

\section{Annexe}

\section{Mathematical Analysis of the Thrombin Generation Curve}

\section{(G. M. Willems, H. C. Hemker).}

The amidolytic activity that we observe in the experiment is the sum of the activities of free thrombin and $\alpha_{2} \mathrm{M}$-bound thrombin. The experimental procedure gives this activity at a series of points in time. It is our purpose to obtain the velocity of thrombin generation alone as a function of time $[\mathrm{g}(\mathrm{t})]$, independent of the breakdown processes.

We can make no assumptions as to the form of $g(t)$ because the enzyme that causes prothrombin activation (prothrombinase) itself increases and decreases as an unknown function of time. We describe the disappearance of thrombin as the sum of two pseudo first order reactions, one giving the inactive product of the 
interaction of antithrombin III and thrombin (AT III-T) and minor amounts of other inactive forms of thrombin and the other the amidolytically active complex of $\alpha_{2}$-macroglobulin and thrombin $\left(\alpha_{2} \mathrm{M}-\mathrm{T}\right)$. (see discussion for experimental justification).

The chemical model can be represented by a set of differential equations that describes the relations between the reaction velocities and the concentrations of the reactants in the system. We will use the following symbols:

$\mathrm{A}(\mathrm{t})=$ amidolytic activity found at time $\mathrm{t}$

$\mathrm{P}(\mathrm{t})=$ prothrombin concentration at time $\mathrm{t}$

$\mathrm{T}(\mathrm{t})=$ thrombin concentration at time $\mathrm{t}$

$\mathrm{M}(\mathrm{t})=\alpha_{2} \mathrm{M}$-thrombin concentration at time $\mathrm{t}$

$\mathrm{g}(\mathrm{t})=$ thrombin generation from prothrombin as a function of time

$\mathrm{k}_{1} \quad=$ pseudo first order rate constant for the binding of thrombin to $\alpha_{2} \mathrm{M}$

$\mathrm{k}_{2}=$ pseudo first order rate constant for the binding of thrombin to AT III

$\mathrm{f}=$ the ratio of the enzymatic activity of one mole of $\alpha_{2} \mathrm{M}-\mathrm{T}$ over that of one mole of thrombin

The subcripts $t h r$ and $m c r$ will indicate the activities due to thrombin and to $\alpha_{2} \mathrm{M}$-thrombin respectively, the total activity is unsubscripted.

The amidolytic activity will be expressed in thrombin equivalent-amounts, so that $\mathrm{A}=\mathrm{T}$ in a solution containing only thrombin and $\mathrm{A}=\mathrm{f}$.M in the presence of $\alpha_{2} \mathrm{M}$-thrombin only.

At any moment the net velocity of thrombin formation will be equal to the sum of the velocity of thrombin generation from prothrombin and the velocity of thrombin breakdown:

$$
\frac{d}{d t} T(t)=g(t)-k_{1} T(t)-k_{2} T(t) \quad(T[o]=0)
$$

The velocity of the formation of $\alpha_{2} \mathrm{M}$-thrombin is proportional to the concentration of free thrombin,

$\frac{\mathrm{d}}{\mathrm{dt}} \mathrm{M}(\mathrm{t})=\mathrm{k}_{1} \mathrm{~T}(\mathrm{t}) \quad(\mathrm{M}[\mathrm{o}]=\mathrm{o})$

and the activity measured is the sum of the activities of thrombin and $\alpha_{2} \mathrm{M}$-thrombin:

$A(t)=T(t)+f M(t)$

These equations have the solution

$g(t)=\frac{d}{d t}\left\{A(t)+\left[(1-f) k_{1}+k_{2}\right] \int_{0}^{t} e^{-f k_{1}(t-\tau)} A(\tau) d \tau\right\}$

In order to use this formula we need estimates of $\mathrm{k}_{1}, \mathrm{k}_{2}$ and $\mathrm{f}$ separately. The value $\mathrm{f}$ can be obtained by comparing the amidolytic activity of thrombin with that of $\alpha_{2} \mathrm{M}$-thrombin (see experimental section). If, at any moment $s$ during thrombin generation we stop the conversion of prothrombin (e.g. by the addition of SBTI) then the course of the remaining activity is given by:

$$
\begin{aligned}
& \frac{d}{d t} T(t)=-\left(k_{1}+k_{2}\right) T(t) ; T(s)=T_{s} \\
& \frac{d}{d t} M(t)=k_{1} T(t) ; M(s)=M_{s} \\
& A(t)=T(t)+f M(t)
\end{aligned}
$$

where $t$ is counted from moment $s$ on and $M_{s}$ in the amount of $\alpha_{2} \mathrm{M}$-thrombin present at moment s.

From the formulas 3 it can be derived that:
$A(t)=T_{s} e^{-\left(k_{1}+k_{2}\right)(t-s)}+f\left\{\frac{k_{1}}{k_{1}+k_{2}} T(s)\left[1-e^{-\left(k_{1}+k_{2}\right)(t-s)}\right]+M(s)\right\}$

for $\mathrm{t} \rightarrow \infty$ this gives

$A(\infty)=f\left\{\frac{k_{1}}{k_{1}+k_{2}} T(s)+M(s)\right\}$

so that

$\log [A(t)-A(\infty)]=\log \left\{\frac{(1-f) k_{1}+k_{2}}{k_{1}+k_{2}}\right\} T_{s}-\left(k_{1}+k_{2}\right)(t-s)$

from which it follows that $k_{1}+k_{2}$ can be obtained from the slope of the plot of $\log [\mathrm{A}(\mathrm{t})-\mathrm{A}(\infty)]$ against time. The activity found at some late point(s) in the time curve are taken as $\mathrm{A}(\infty)$. In order to obtain $\mathrm{k}_{1}$ and $\mathrm{k}_{2}$ separately we integrate (2):

$P(0)-P(\infty)=\int_{0}^{\infty} g(\tau) d(\tau) d \tau=A(\infty)+\frac{(1-f) k_{1}+k_{2}}{f k_{1}} A(\infty)$

from which it follows that:

$\mathrm{A}(\infty)=\frac{\mathrm{fk}_{1}}{\mathrm{k}_{1}+\mathrm{k}_{2}} \int_{0}^{\infty} \mathrm{g}(\tau) \mathrm{d} \tau=\frac{\mathrm{fk}_{1}}{\mathrm{k}_{1}+\mathrm{k}_{2}}[\mathrm{P}(\mathrm{o})-\mathrm{P}(\infty)]$

where $\mathrm{P}(\infty)$ is the amount of prothrombin present after the activation is over, so that $\mathrm{P}(0)-\mathrm{P}(\infty)$ is the total amount of thrombin that has been formed during the experiment from formula (6), and equal to the amount of prothrombin converted during the experiment. We calculate $\mathrm{k}_{1}$ as

$k_{1}=\frac{\left(k_{1}+k_{2}\right) A(\infty)}{f[P(0)-P(\infty)]}$

and $\mathrm{k}_{2}$ from:

$\mathrm{k}_{2}=\left(\mathrm{k}_{1}+\mathrm{k}_{2}\right)-\mathrm{k}_{1}$

Once the constants $\mathrm{f}, \mathrm{k}_{1}$ and $\mathrm{k}_{2}$ are known we can use the following rearrangement of formula 2 to calculate $g(t)$ :

$$
\int_{0}^{t} g(\tau) d \tau=A(t)+\frac{\left(k_{1}+k_{2}\right)-f \cdot k_{1}}{k_{1}+k_{2}} e^{-f k_{1} t} \int_{0}^{t} A(t) e^{+f k_{1} \tau} d \tau
$$

In practice $\mathrm{A}(\mathrm{n})$ is obtained at a series of times, $\mathrm{t}(\mathrm{n})$; $\mathrm{n}$ being the running number of the observation. The integral in the right hand term of formula (9) $[\mathrm{I}(\mathrm{n})]$ can be obtained as the area under the curve generated by plotting

$\mathrm{S}(\mathrm{n})=\mathrm{A}(\mathrm{n}) \mathrm{e}^{\mathrm{fk} \mathrm{k}_{1}} \cdot \mathrm{t}(\mathrm{n})$

against $t(n)$, so that

$I(n)=1 / 2 \quad \sum_{1}^{n}[(t(n)-t(n-1)) \cdot(s(n)+s(n-1))]$

The amount of thrombin that would have been formed at the moment of observation if no inactivation had taken place then is obtained as:

$\mathrm{T}(\mathrm{n})=\mathrm{A}(\mathrm{n})+\left[\left(\mathrm{k}_{1}+\mathrm{k}_{2}-\mathrm{fk}_{1}\right) /\left(\mathrm{k}_{1}+\mathrm{k}_{2}\right)\right] \cdot \mathrm{e}^{-\mathrm{fk} \mathrm{k}_{1} \cdot \mathrm{t}(\mathrm{n})} \cdot \mathrm{I}(\mathrm{n})$

The following series of Basic commands, operating on the arrays $A(n)$ and $t(n)$ carries out these calculations.

$100 \mathrm{CE}=\mathrm{F}^{*} \mathrm{~K} 1: \mathrm{CT}=(\mathrm{K} 1+\mathrm{K} 2-\mathrm{CE}) /(\mathrm{K} 1+\mathrm{K} 2)$

$110 \mathrm{~A}(\emptyset)=\emptyset: \mathrm{T}(\emptyset)=\emptyset: \mathrm{IN}=\emptyset: \mathrm{SN}=\emptyset$

120 FOR $N=1$ TO $E$ : REM E = number of data points

$130 \mathrm{~S}=\mathrm{A}(\mathrm{N}) * \operatorname{EXP}[\mathrm{CE} * \mathrm{~T}(\mathrm{~N})]$ 
$140 \mathrm{I}=\mathrm{IN}+[\mathrm{T}(\mathrm{N})-\mathrm{T}(\mathrm{N}-1)] *[(\mathrm{~S}+\mathrm{SN})] / 2$

$150 \mathrm{TT}(\mathrm{N})=\mathrm{A}(\mathrm{N})+\mathrm{CT} * \mathrm{I} * \operatorname{EXP}[-\mathrm{CE} * \mathrm{~T}(\mathrm{~N})]$

$160 \mathrm{~V}(\mathrm{~N}-1)=[\mathrm{TT}(\mathrm{N})-\mathrm{TT}(\mathrm{N}-1)] /[\mathrm{T}(\mathrm{N})-\mathrm{T}(\mathrm{N}-1)]$

$170 \mathrm{SN}=\mathrm{S}: \mathrm{IN}=\mathrm{I}$

180 NEXT N

It will yield the array $\mathrm{TT}(\mathrm{N})$ and $\mathrm{V}(\mathrm{N})$ that, when plotted against $\mathrm{T}(\mathrm{N})$ (sampling time) give the total amount of prothrombin activated and the velocity of prothrombin conversion as a function of time.
This routine is the core of the program "Thrombinoscope" (24) that a) stores the experimental data on disk b) calculates prothrombinase activity c) stores the results of the calculation on disk and d) displays the data and results in graphic and/or alphanumeric format on the monitor or the printer. The program was developed in Applesoft Basic on an Apple IIe personal computer with $128 \mathrm{k}$ RAM and Applesoft in ROM. Both data obtained at regular and at irregular intervals can be accomodated. It also contains the subprogram "Stopwatch" that is used to record sampling and stopping times from pipettes provided with a pushbutton. The program can be obtained from the authors.

\title{
R. J. LEFKOWITZ E. LINDENLAUB (Eds.) \\ Adrenergic Receptors: Molecular Properties and Therapeutic Implications
}

\author{
Symposium St.-Paul-de-Vence, France, October 21st-24th, 1984
}

\section{Symposia Medica Hoechst 19}

The ubiquity and importance of the receptors for catecholamines is obvious. Catecholamines are regulators of such diverse metabolic and physiological functions that their receptors are definitely important.

Moreover, the adrenergic receptors provide model systems for trying to dissect and understand the two major pathways of signal transduction through the plasma membrane. The first is the adenylate cyclase system. The beta receptors stimulate the enzyme. The alpha 2 receptors inhibit the enzyme.

The alpha ${ }_{1}$-adrenergic receptors, which are related to changes in calcium flux and to changes in phosphatidyl inositol breakdown. Finally, there are the obvious clinical and therapeutic implications of work on these receptors. All the adrenergic receptors can be manipulated therapeutically through the use of a wide variety of agonist and antagonist agents. Moreover, the function of these receptors, as well as various of their coupled effector components, can be deranged by both congenital and acquired pathophysiological conditions. 